\author{
S. Sheeju Selva Roji \\ R. Edwin Raj \\ D.F. Melvin Jose
}

DOI: $10.21278 /$ TOF.40307

ISSN 1333-1124

eISSN1849-1391

\title{
EXPERIMENTAL EVALUATION OF PERFORMANCE AND EMISSION CHARACTERISTICS OF A DIESEL ENGINE FUELLED WITH NEEM METHYL ESTER
}

\begin{abstract}
Summary
The dwindling fossil fuel resources and the environmental degradation have spurred research interest to find better renewable alternative energy sources. Biodiesel is one such viable promising alternative fuel, which can be extracted from various renewable vegetable oils. In the present study, biodiesel extracted from neem oil is characterized for engine performance and emission analysis is done at various compression ratios (CR) and fuel blends. The brake thermal efficiency (BTE) of the blend B20 is considerably higher than that of diesel at CR 18, 20, and 22. The specific fuel consumption (SFC) increases with diesel blends due to a higher calorific value of diesel in comparison with biodiesel. All the biodiesel blends had lower carbon monoxide (CO) emissions compared with diesel, which indicates better combustion due to the presence of inherent oxygen. At lower CRs, the in-cylinder temperature is lower, which in turn reduces the nitrogen oxide $\left(\mathrm{NO}_{\mathrm{X}}\right)$ emission. The overall engine performance is optimum at CR of 18 with the NB20 fuel blend.
\end{abstract}

Key words: $\quad$ Biodiesel, Compression ratio, Engine performance, Emission

\section{Introduction}

Industrial, technological and socio-economic development of a nation depends on the easy availability of energy at affordable rates. Every aspect of day-to-day life depends on energy, particularly fuel for the transport of goods and people. Currently, most of the global transportation needs are met by petroleum sources, which are in high demand and hence their prices soar [1]. Fossil fuels fulfil $80 \%$ of the world's energy needs. The emission of greenhouse gases and hydrocarbon by the combustion of fossil fuels contributes greatly towards air pollution and global warming. Among various options investigated for automotive fuels, the extraction of biodiesel from vegetable oils seems to be the best as vegetable oils can contribute to reducing automotive pollution [2]. For any agriculture dependent country like India, it will not be economical to use edible vegetable oil for biodiesel extraction as it is in great demand for food processing. Hence, it is important to find a great number of viable non-edible vegetable oil sources for the production of biodiesel and to reduce the dependability on depleting fossil fuels. More than 35 million tons of non- 
edible vegetable oils, mainly jatropha oil, karanja oil, mahua oil, neem oil, and rubber seed oil, is produced in India per year [3]. There are some problems that need to be addressed in using vegetable oils as fuel for engines due to their high viscosity [4]. The physical properties of vegetable oils such as viscosity, molecular weight, and density have higher values than those of diesel, which hinders their direct usage in the diesel engine and demands the thinning of oil to modify the fuel properties to match those of the fossil diesel [1].

High boiling point of biodiesel affects vaporization, whereas its high viscosity hinders atomization which demands blending. Injection parameters such as injection pressure, spray penetration, injection timing, and compression ratio were studied in detail elsewhere $[5,6,7]$. Nabi et al. [8] extracted biodiesel by the transesterification process from non-edible neem oil and tested it in a $\mathrm{CI}$ engine which showed a reduction in the exhaust emissions, especially $\mathrm{CO}$ and smoke. They also reported a slight increase in the nitrogen oxides (NOx) emission when biodiesel mixtures were used. The presence of oxygen and aromatics in the biodiesel contributed to the reduction in smoke, $\mathrm{CO}$ and the increase in the NOx emission. When the exhaust gas was re-circulated, the NOx emission of diesel-biodiesel blends was reduced.

In this paper, highly viscous non-edible neem oil was extracted using two stage esterification. The extracted neem methyl ester was tested for its fuel properties under standard test conditions. Different blends of biodiesel in the ratios of B20, B40, B60, and $\mathrm{B} 100$ along with diesel were tested for their performances at various compression ratios. The combustion phenomena along with exhaust emission characteristics were analysed and the results were compared to optimize the design parameters.

\section{Biodiesel extraction process}

Neem (Azadirachta indica) is a potential non-edible oil source available in more than 30 countries spreading across Asia, Africa, Central and South America and it is a common species in India and the Indian subcontinent including Nepal, Bangladesh, Pakistan and Sri Lanka. Roughly twenty million mature neem trees in India can provide approximately 0.1 million tons of kernels every year [1]. After sun drying, the kernels are separated from the neem seeds and screw-pressed to extract the oil. The acid value of raw oil is determined by titrating it against the standard potassium hydroxide solution using phenolphthalein as an indicator. Since the acid value of the neem oil is very high, a two stage esterification process is carried out [9]. In the first stage, sulphuric acid was used as the catalyst for esterification and in the second, stage potassium hydroxide (alkaline).

\section{Evaluation of fuel properties}

The biodiesel extracted from the neem oil is characterized for its physical and chemical properties. The viscosity of the biodiesel is measured by a Brookfield viscometer and a Pensky-Marten Closed Tester is used to determine its flash point and the fire point. A Parr calorimetric thermometer is used to measure the calorific value of the biodiesel. The acid value of the neem oil is reduced from $35 \mathrm{mg} \mathrm{KOH} / \mathrm{g}$ to $1.46 \mathrm{mg} \mathrm{KOH} / \mathrm{g}$ through the two stage transesterification process. Similarly, the viscosity of raw neem oil is reduced from $39.82 \mathrm{cSt}$ to $3.2 \mathrm{cSt}$, which is slightly higher than that of diesel. The energy content of biodiesel is only $4 \%$ lower than that of diesel. The important chemical and physical properties of the extracted biodiesel are tabulated and compared with those of the standard biodiesel and diesel in Table 1. The tested properties of neem methyl ester are found to be in reasonable agreement with the ASTM standard D6751-02 for biodiesel which demands no major modification in order to be used in the conventional diesel engine. 
Table 1 Comparison of neem oil-based biodiesel properties with diesel

\begin{tabular}{ccccc}
\hline Property & $\begin{array}{c}\text { Test } \\
\text { Procedure }\end{array}$ & $\begin{array}{c}\text { Biodiesel-Standard } \\
\text { ASTM D6751-02 }\end{array}$ & $\begin{array}{c}\text { Neem oil based } \\
\text { Biodiesel }\end{array}$ & Diesel \\
\hline Specific Gravity at $30^{\circ} \mathrm{C}$ & ASTM D4052 & $0.87-0.90$ & 0.8834 & 0.8236 \\
Kinematic Viscosity at $40^{\circ} \mathrm{C} \mathrm{mm}^{2} / \mathrm{s}$ & ASTM D445 & $1.9-6.0$ & 3.2 & 3.18 \\
Heating Value $\mathrm{MJ} / \mathrm{kg}$ & ASTM D240 & - & 40.8 & 44.1 \\
Flash Point ${ }^{\circ} \mathrm{C}$ & ASTM D93 & 130 & 78 & 68 \\
Cloud Point $^{\circ} \mathrm{C}$ & ASTM D2500 & -3 to 12 & 3 & 17 \\
Pour Point ${ }^{\circ} \mathrm{C}$ & ASTM D97 & -1.5 to 10 & 0.12 & -20 \\
Carbon residue $\%$ & - & $<0.3$ & & 0.17 \\
\hline
\end{tabular}

\section{Experimental setup}

A single cylinder, four stroke, water cooled, variable compression ratio (VCR) engine is used to study the influence of the compression ratio (CR) and fuel on the performance and emission characteristics of an engine. The engine specifications are given in Table 2. The experimental setup is properly instrumented and connected with the data acquisition system for the dynamic measurement and recording of parameters such as crank-angle, cylinder pressure, air and fuel flow rates, temperatures, etc. Provisions are also made for measuring the exhaust gas temperature (EGT) and the cooling water inlet/outlet temperatures. A specially designed arrangement is provided for diverting the exhaust gases to a sampling line without increasing the back pressure and for analysing them using a quintox multi-gas analyser for measuring the levels of pollutant gases.

Table 2 Specifications of the engine used for the performance analysis

\begin{tabular}{cc}
\hline Particulars & Details \\
\hline Make & KIRLOSKAR \\
No. of Cylinders & Single \\
Cooling & Water \\
Bore \& Stroke & $87.5 \mathrm{~mm} \times 110 \mathrm{~mm}$ \\
Cycle & Four stroke \\
Maximum Power & $5 \mathrm{~kW}$ \\
Speed & $1450-1600 \mathrm{RPM}$ \\
Compression Ratio & $16-22$ \\
Injection Timing & $23^{\circ}$ BTDC \\
Loading & Auto loading \\
\hline
\end{tabular}

\section{Results and discussion}

5.1 Brake thermal efficiency and specific fuel consumption

The variation in the brake thermal efficiency (BTE) of different biodiesel blends at different CRs is shown in Figure 1. It has been observed that the brake thermal efficiency of the blend NB20 is slightly higher than that of the standard diesel at all CRs. The highest brake thermal efficiency is attained with the blend NB20 at CR 18. By increasing the compression ratio of the engine, the brake thermal efficiency improves; however, beyond CR 18 it decreases. This phenomenon is also reflected in the heat release rate and the cylinder pressure diagram plotted with respect to the crank angle (Figures 2 and 3). The heat release analysis is based on the changes in the cylinder gas pressure and the cylinder volume during the cycle. At lower CRs, the heat release rate is higher, which can be attributed to significant air/fuel mixing and better penetration of fuel during injection. Generally, the heat release rate of 
S. S. S. Roji, R. E. Raj, D. F. M. Jose
Experimental Evaluation of Performance and Emission Characteristics of a Diesel Engine Fuelled with Neem Methyl Ester

diesel in comparison with biodiesel is higher due to reduced viscosity, which leads to better spray formation. But, the brake thermal efficiency of biodiesel is always slightly better than that of diesel due to the presence of oxygen, which facilitates the combustion process $[10,11]$. The better lubricity property of biodiesel also improves its performance [12].

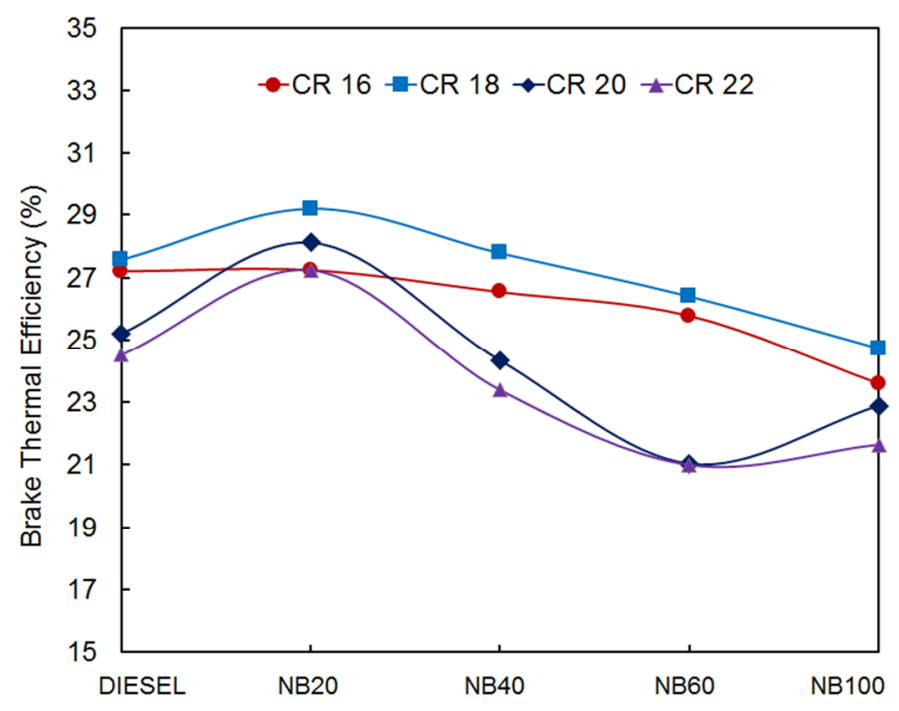

Fig. 1 Comparison of BTE at different CRs between different biodiesel blends and diesel
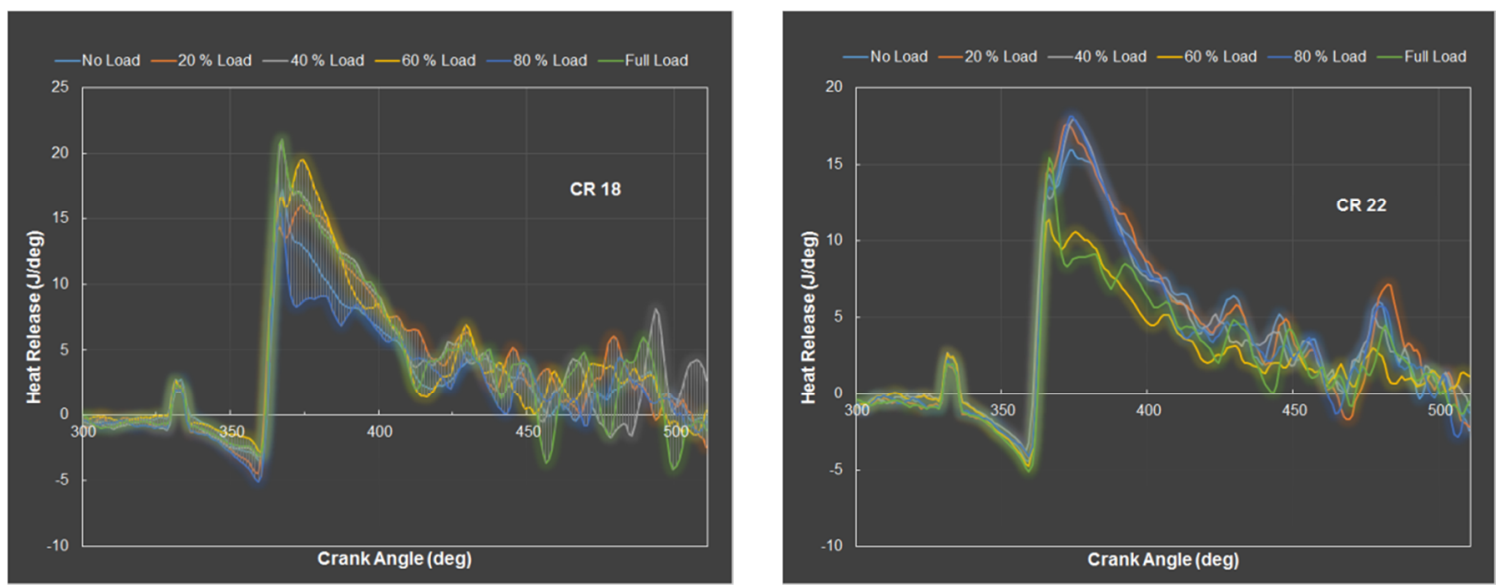

Fig. 2 Heat release rate of the engine at CRs 18 and 22 when using biodiesel as fuel
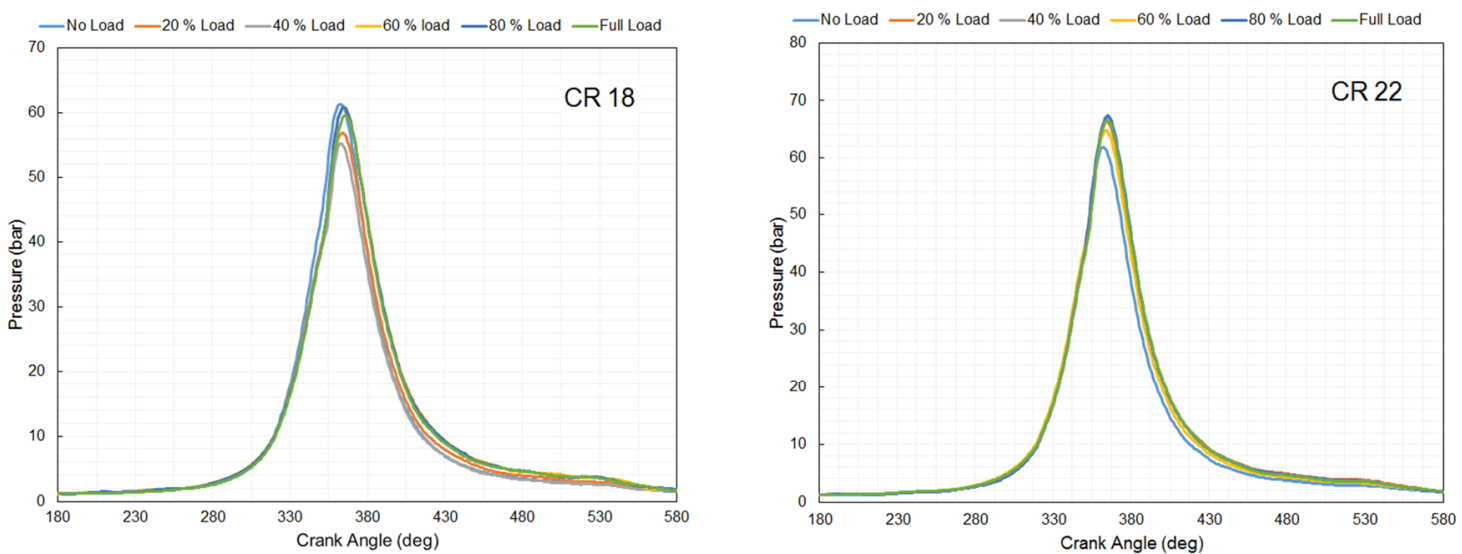

Fig. 3 Cylinder pressure of the engine at CRs 18 and 22 when using biodiesel as fuel 
The variation in specific fuel consumption (SFC) of the biodiesel blends at different compression ratios is shown in Figure 4. During the engine testing with different combinations of compression ratios and fuel blends, the synergic effect is observed at the compression ratio of 18 where the specific fuel consumption is minimal and BTE is maximal with most of the fuel blends. The SFC of the NB20 blend is lower than that of all other blends at compression ratios 16 and 18, whereas at CRs of 20 and 22 the trend is absurd, which may be due to the experimental error. In general, with higher blends, the SFC increases due to the decrease in the calorific value of the higher blends since it is calculated on the weight basis. The density of NB100 is $4 \%$ higher than that of diesel. The higher densities of biodiesel blends cause higher mass injection for the same volume at the same injection pressure [13].

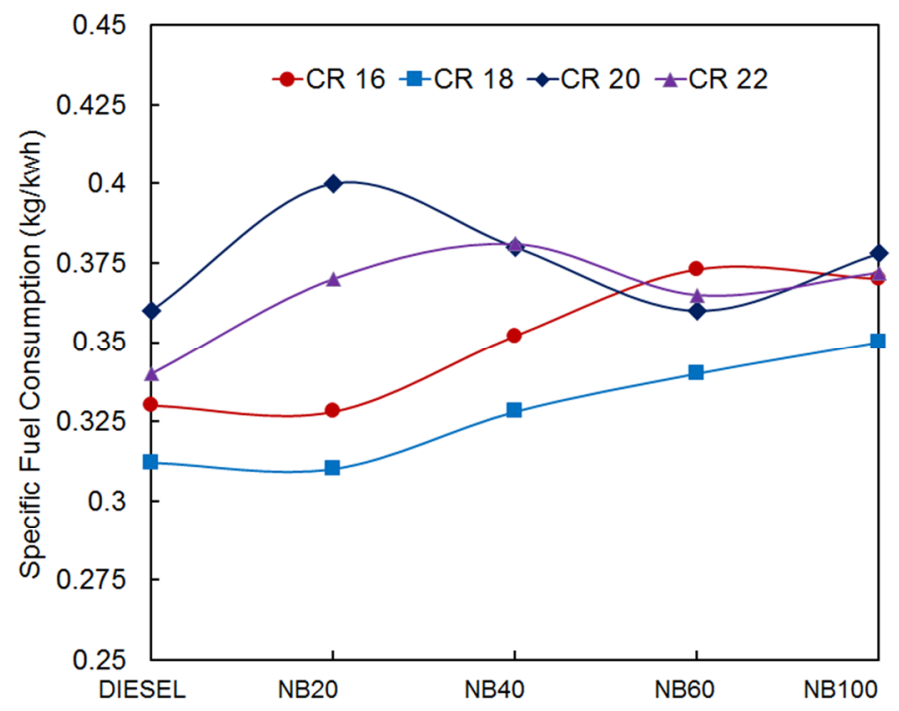

Fig. 4 Comparison of SFC at different CRs between different biodiesel blends and diesel

\subsection{Emission analysis}

The emission parameters have to be corroborated by the performance results in order to consider biodiesel as a viable alternative source of automotive fuel. The emission parameters such as carbon monoxide (CO), hydrocarbon (HC), smoke density, and nitrogen oxide $\left(\mathrm{NO}_{\mathrm{X}}\right)$ are analysed.

\subsubsection{Exhaust Gas Temperature}

The variation in exhaust gas temperature (EGT) of the biodiesel blends at different CRs is presented in Figure 5. The EGT is an indirect reflection of the fuel combustion condition inside the cylinder. It is observed that the EGT decreases with the increasing biodiesel concentration in comparison with diesel. When the biodiesel concentration is increased, the viscosity of the blend is also increased, which results in a lower EGT due to the combustion process deterioration. Moreover, a higher CR provides a higher temperature at the start of combustion enables spontaneous combustion, which leads to a lower EGT. This phenomenon is observed with all the blends, which results in reduced EGTs at higher CRs. The presence of oxygen in the biodiesel and the lower calorific value of biodiesel in comparison with diesel are the possible causes of the reduction in EGT and higher performance [14]. 


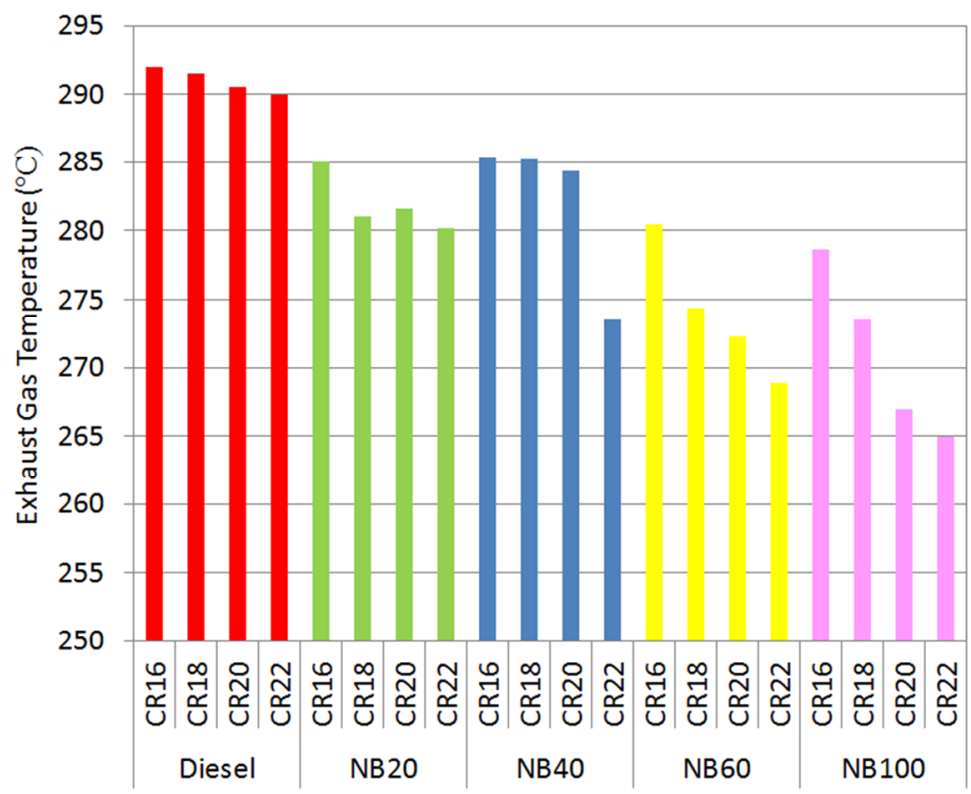

Fig. 5 Comparison of EGT at different CRs between different biodiesel blends and diesel

\subsubsection{Carbon Monoxide Emission}

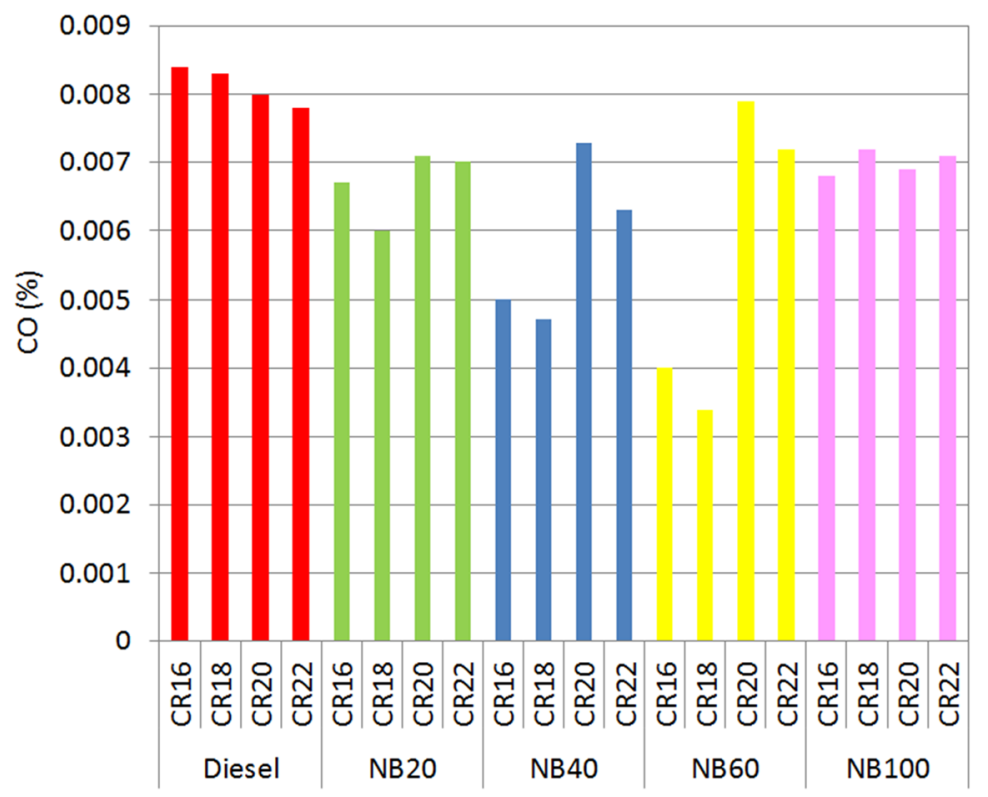

Fig. 6 Variation in the amount of CO at different CRs of different biodiesel blends and diesel

Incomplete combustion of carbon leads to the formation of carbon monoxide (CO) which is a toxic combustion product. The formation of CO takes place when the oxygen for combustion is in insufficient quantity or not available in the vicinity. Initially, at no load condition, the cylinder temperatures might be too low, which leads to incomplete combustion. The $\mathrm{CO}$ emissions of each experiment are recorded carefully and are shown in Figure 6. All biodiesel blends exhibit lower $\mathrm{CO}$ emissions compared with diesel, which may be due to better combustion of biodiesel blends because of the presence of inherent oxygen [15]. It is also observed that $\mathrm{CO}$ emission decreases with an increase in the compression ratio up to 18. At lower compression ratios, the in-cylinder temperature is also low, which leads to the formation of more CO. Minimum values of CO are found with the NB60 blend at CRs 16 and 18. 


\subsubsection{Hydro Carbon Emission}

Unburned fuel may escape through exhaust as hydrocarbon (HC). Hydrocarbon emissions from diesel engines vary widely with different operating modes. The key component of brown haze of smog is hydrocarbon, which plagues many urban areas causing serious health problems to humans. Incomplete mixing of fuel and air and the quenching of the oxidation process are the main causes of $\mathrm{HC}$ emissions from diesel engines. The variation in the hydrocarbon emission level with biodiesel blends at different CRs is depicted in Figure 7. It is observed that the HC emission of biodiesel blends is lower than that of diesel due to higher oxygen content in biodiesel, which results in more complete combustion. The figure also shows that the $\mathrm{HC}$ emission of various blends is higher at higher compression ratios, which may be due to the improper mixing of fuel and air. Lower emission of $\mathrm{HC}$ of biodiesel is reported by some researchers [16] but, at the same time, higher emission of $\mathrm{HC}$ of biodiesel is also reported, which is attributed to improper atomization of the fuel [17].

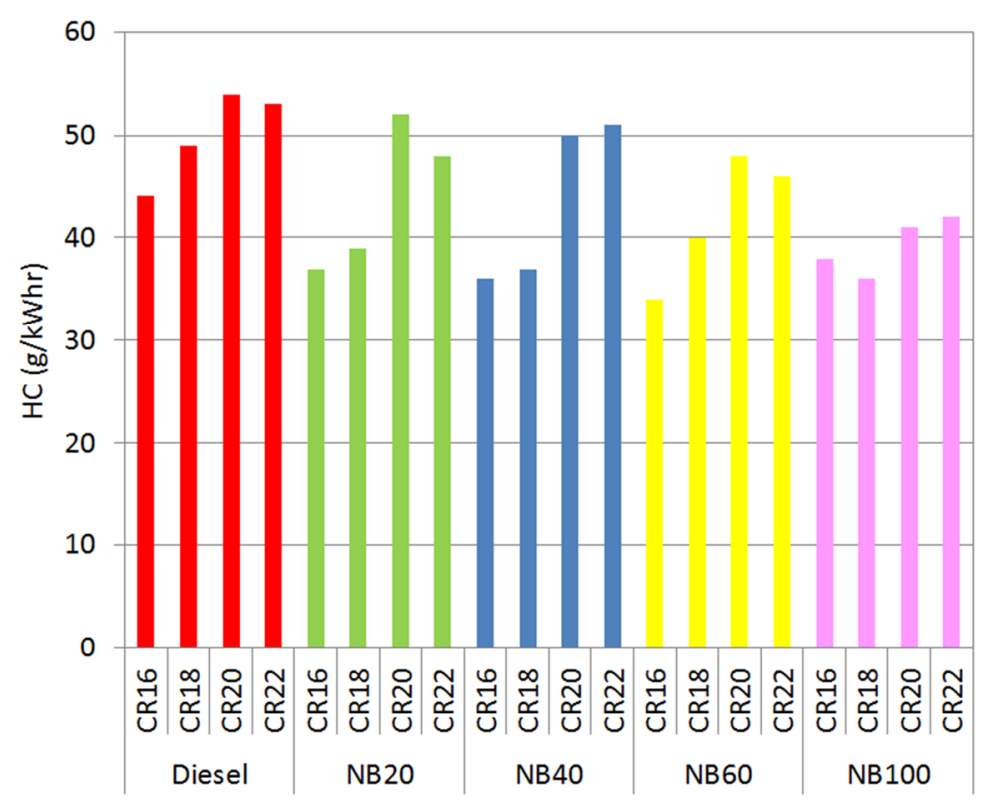

Fig. 7 Variation in the amount of $\mathrm{HC}$ at different CRs of different biodiesel blends and diesel

\subsubsection{Smoke Density}

Smoke is nothing but solid soot particles suspended in the exhaust. The variation in the smoke density of different biodiesel blends and diesel at different compression ratios is shown in Figure 8. The smoke level decreases sharply with an increase in the proportion of biodiesel in the blends at all CRs, which may be attributed to the relatively improved burning characteristics of biodiesel blends due to the basic difference in their chemical structure and the presence of oxygen in the molecule of the biodiesel. It can also be seen that the smoke level increases sharply with an increase in the compression ratio of diesel and of all the biodiesel blends, mainly due to the lower air-fuel ratio when larger quantities of fuel are injected into the combustion chamber. In that case, much of the fuel goes into the exhaust unburned. However, beyond CR 20, the smoke emission is reduced with all the biodiesel blends and diesel due to the sudden and spontaneous combustion of the fuel [15]. The minimum smoke emission is produced with B100 at CR 16. 


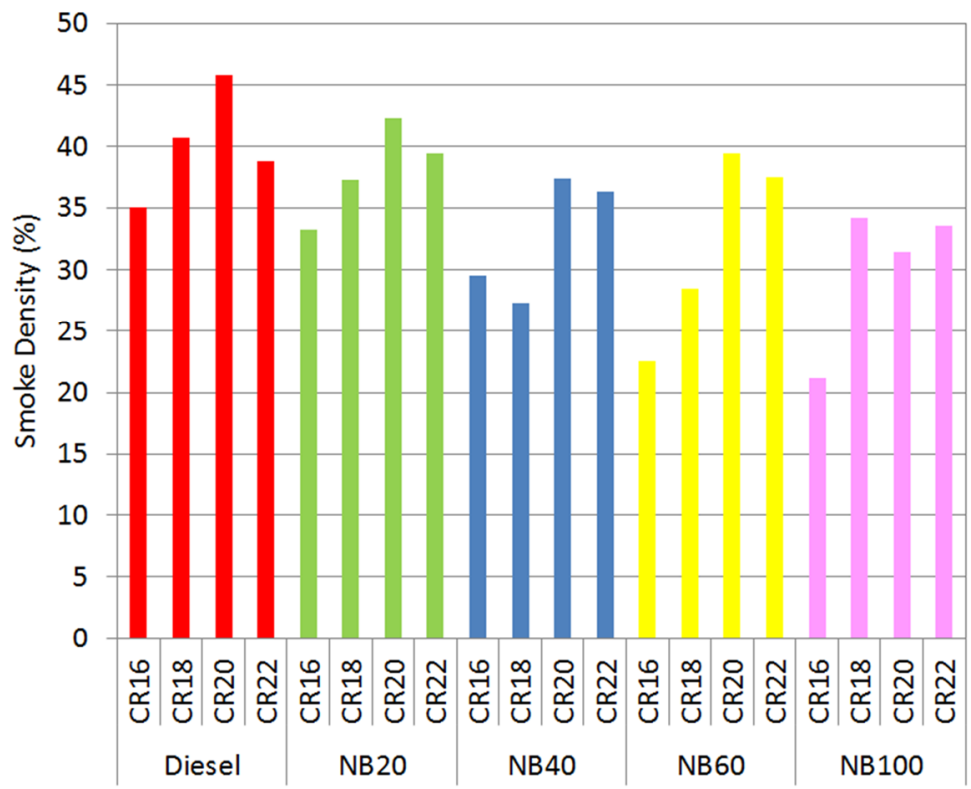

Fig. 8 Variation in smoke density at different CRs of different biodiesel blends and diesel

\subsubsection{Nitrogen Oxide Emission}

One of the most critical emissions from diesel and biodiesel engines is the nitrogen oxide $\left(\mathrm{NO}_{\mathrm{X}}\right)$ emission. The variation in the amount of $\mathrm{NO}_{\mathbf{X}}$ with biodiesel blends at different compression ratios is shown in Figure 9. A lower CR reduces the in-cylinder temperature, which in turn reduces the flame temperature during combustion, which reduces suppress the $\mathrm{NO}_{\mathrm{X}}$ emission. The lowest $\mathrm{NO}_{\mathrm{X}}$ emission is noticed withNB20 at CR16. On the other hand, a fairly gradual positive slope of biodiesel blend shows that it has a small influence on the $\mathrm{NO}_{\mathrm{X}}$ emission. The $\mathrm{NO}_{\mathrm{X}}$ emission of diesel is comparatively higher at all compression ratios in comparison with all the blends of biodiesel [18]. It is also known that the $\mathrm{NO}_{\mathrm{X}}$ formation increases with the concentration of biodiesel as it is an oxygenated fuel. It is quite obvious that with biodiesel, due to improved combustion, the temperature in the combustion chamber can be expected to be higher and a higher amount of oxygen is also present, which leads to the formation of a higher quantity of $\mathrm{NO}_{\mathrm{X}}$ in biodiesel-fuelled engines [17].

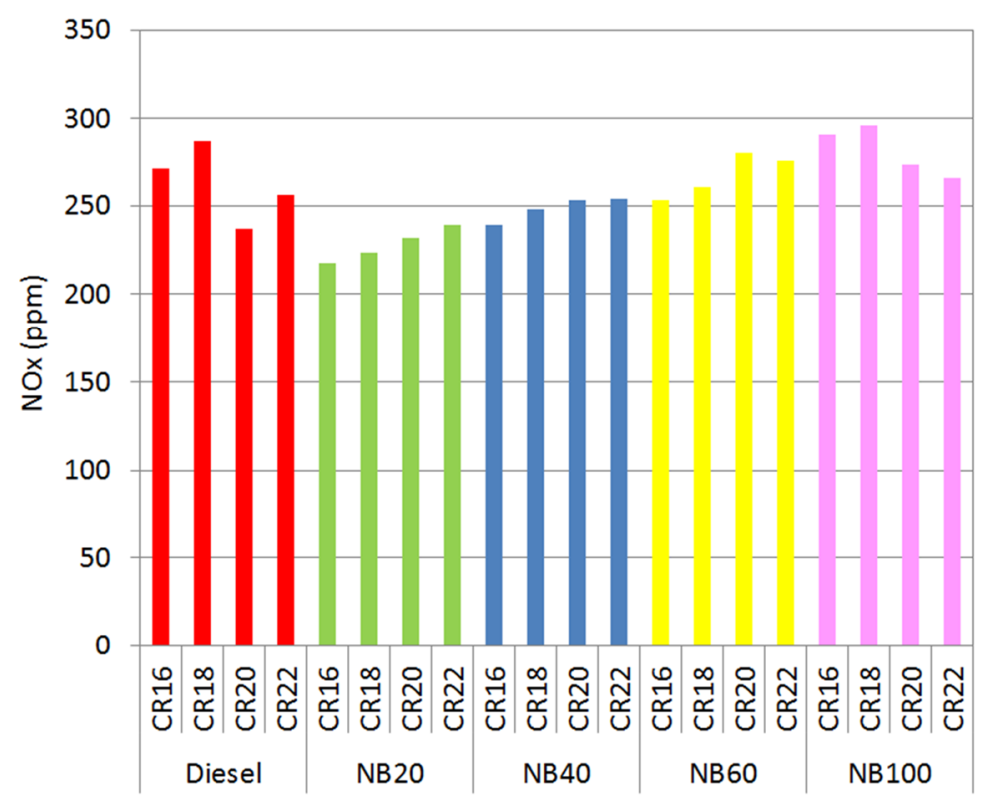

Fig. 9 Variation in the amount of $\mathrm{NO}_{\mathrm{X}}$ at different $\mathrm{CRs}$ of different biodiesel blends and diesel 
Fuelled with Neem Methyl Ester

\section{Conclusion}

The effect of compression ratio and biodiesel blends on the diesel engine performance and emission characteristics is analysed in this study. It is found that the brake thermal efficiency of the blend NB20 is considerably higher than that of diesel at CR 18, 20, and 22 and it is lowest with NB100, which is due to the reduction in the calorific value and an increase in the fuel viscosity. The SFC, in general, is found to increase with the increasing proportion of biodiesel in the blends. The SFC of the NB20 blend is lower than that of all other blends at CRs of 16 and 18, whereas at CRs of 20 and 22, the trend is absurd, which may be due to the experimental error. The SFC increases with diesel blends due to the higher calorific value of diesel in comparison with biodiesel.

All blends of biodiesel had lower $\mathrm{CO}$ emissions compared with diesel, which indicates better combustion due to the presence of inherent oxygen. It is also observed that the $\mathrm{CO}$ emission decreases at CRs of up to 18 and increases thereafter due to improper combustion. The HC emission also decreases due to the presence of oxygen in biodiesel. At a lower CR, the in-cylinder temperature is lower, which in turn reduces suppresses the $\mathrm{NO}_{\mathrm{X}}$ emission. The smoke level decreases sharply with an increase in the proportion of biodiesel in the blends for all CRs, which may be attributed to the relatively improved burning characteristics of biodiesel. The overall performance of the tested diesel engine using the NB fuel is optimum at CR of 18 with the NB20 fuel blend.

\section{REFERENCES}

[1] Anindita Karmakara, Subrata Karmakar, Souti Mukherjee. Biodiesel production from neem towards feedstock diversification: Indian perspective. Renewable and Sustainable Energy Reviews 2012; 16(1): 1050- 1060. DOI: 10.1016/j.rser.2011.10.001

[2] Senthil R, Ravichandiran N, Silambarasan R. Performance and emission characteristics of a diesel engine with a zirconium dioxide-coated piston and nerium and mahua methyl esters used as fuels. Transactions of FAMENA 2015; 39(2): 87-96.

[3] Sukumar Puhan,Vedaraman N, Rambrahamam BV, Nagarajan G. Mahua seed oil: A Source of renewable energy in India. Journal of Scientific and Industrial Research 2005; 64: 890-896.

[4] Kalam MA, Masjuki HH. Emissions and deposit characteristics of a small diesel engine when operated on preheated crude palm oil. Int J of Biomass and Bioenergy 2004; 27: 289-297.

DOI: 10.1016/j.biombioe.2004.01.009

[5] Zhong L, Sigh IP, Han J, Lai MC, Henein NA. Effect of cycle-to-cycle variation in the injection pressure in a common rail diesel injection system on engine performance. SAE International SP-1739, 2003; 1928. DOI: $10.4271 / 2003-01-0699$

[6] Raheman H, Ghadge SV. Performance of diesel engine with biodiesel at varying compression ratio and ignition timing. Fuel2008; 87: 2659-66. DOI: 10.1016/j.fuel.2008.03.006

[7] Melvin Jose DF, Edwin Raj R, Robert Kennedy Z. An extraction and performance analysis of rubber seed-methyl ester on an IC engine at various compression ratios. Int J of Green Energy 2014; 11: 1-14.

[8] Nabi MN, Akhter MS, Shahadat MMZ. Improvement of engine emissions with conventional diesel fuel and diesel-biodiesel blends. Bioresource Technology 2006; 97(1): 372-378. DOI: 10.1016/j.biortech.2005.03.013

[9] Satyanarayana M, Muraleedharan C. Methyl Ester Production from Rubber Seed oil Using Two-Step Pretreatment Process. Int J of Green Energy 2010; 7:84-90. DOI: 10.1080/15435070903501290

[10] Agarwal AK. Biofuels (alcohols and biodiesel) applications as fuels for internal combustion engines. Prog Energy Combustion Science 2007; 33: 233-271. DOI: 10.1016/j.pecs.2006.08.003

[11] Kumaran D, Rajendran M, Kumaravelan R, Sathish Gandhi VC. Testing of three-fuel mixture in a fourstroke single cylinder direct injection diesel engine. Transactions of FAMENA 2013; 37(3): 75-86.

[12] Peterson CL, Wagner GL, Auld DL. Vegetable oil substitution for diesel fuel. Transactions of the ASAE1983; 26: 322-327. DOI: 10.13031/2013.33929

[13] Heywood JB. Internal combustion engine fundamentals. 1988; McGraw Hill Book Co. 
S. S. S. Roji, R. E. Raj, D. F. M. Jose
Experimental Evaluation of Performance and Emission Characteristics of a Diesel Engine Fuelled with Neem Methyl Ester

[14] Arul Mozhi Selvan V, Anand RB, Udayakumar M. Combustion characteristics of diesohol using bio diesel as an additive in a direct injection ignition engine under various compression ratios. Energy \& Fuels 2009; 23: 5413-5422. DOI: 10.1021/ef900587h

[15] Ramadhas AS, Muraleedharan C, Jayaraj S. Performance and emission evaluation of a diesel engine fueled with methyl esters of rubber seed oil. Renewable Energy2005; 30: 1789 - 1800. DOI: 10.1016/j.renene.2005.01.009

[16] Jindal S, Nandwana BP, Rathore NS, Vashistha V. Experimental investigation of the effect of compression ratio and injection pressure in a direct injection diesel engine running on Jatropha methyl ester. Applied Thermal Energy2010; 30: 442-448. DOI: 10.1016/j.applthermaleng.2009.10.004

[17] Muralidharan K, Vasudevan D. Performance, emission and combustion characteristics of a variable compression ratio engine using methyl esters of waste cooking oil and diesel blends. Applied Energy2011; 88: 3959-3968. DOI: 10.1016/j.apenergy.2011.04.014

[18] Pesic R, Milojevic S. Efficiency and ecological characteristics of a VCR diesel engine. Int J of Automotive Technology 2013; 14: 675-681. DOI: 10.1007/s12239-013-0073-4

Submitted: $\quad 23.8 .2014$

Accepted: $\quad 20.9 .2016$
S. Sheeju Selva Roji

Department of Mechanical Engineering, University College of Engineering, Nagercoil, Nagercoil-629004, India Email:sselvaroji@gmail.com

R. Edwin Raj Department of Mechanical Engineering, St. Xavier's Catholic College of Engineering, Nagercoil - 629003, India Email:redwinraj@gmail.com, Telephone No.+91-9442054535

D.F. Melvin Jose

Department of Mechanical Engineering, Sri Vellappally Natesan College of Engineering, Alappuzha-690503, India Email: melvin_05@rediffmail.com 